\title{
Os filmes como instrumento didático-pedagógico para o ensino de geografia
}

\author{
Films as a didactic-pedagogical instrument for the teaching of geography
}

\author{
Rita Jaqueline Nogueira Chiapetti'; Glauber Magalhães de Freitas ${ }^{\text {II }}$
}

\begin{abstract}
RESUMO
Em plena era tecnológica tem se tornado cada vez mais necessário o uso de tecnologias educacionais em sala de aula, a fim de aproximar o aluno do mundo que o cerca, e no caso do ensino de Geografia especialmente, já que ele tem compromisso com a formação de cidadãos do mundo. Como objetivo principal se propõe a analisar o filme como um instrumento didático-pedagógico no ensino de Geografia. O método empregado é o da pesquisa bibliográfica, sendo a leitura analítica a principal técnica desse tipo de pesquisa, pois é através dela que se podem identificar as informações e os dados contidos na bibliografia selecionada, bem como verificar as relações existentes entre elas, de modo a analisar a sua consistência para serem utilizadas na pesquisa. Como resultados da pesquisa, as tecnologias educacionais vêm ganhando cada vez mais espaço nas escolas, pois funcionam com uma forma de alicerçar o ensino e aprendizagem dos conteúdos curriculares. O filme é visto pelos autores pesquisados como instrumento didático-pedagógico atrativo para o ensino de Geografia, na compreensão da relação natureza-sociedade, contribuindo significativamente para o processo de ensino-aprendizagem dos conteúdos geográficos. Conclui-se que seu uso deve sempre contar com um bom planejamento das aulas por parte dos professores, visto que por meio do filme é possível despertar o interesse, melhorar a participação, estimular o debate e a reflexão crítica dos alunos.
\end{abstract}

Palavras-chave: Ensino de Geografia; Filme; Instrumento didático-pedagógico

\section{ABSTRACT}

In the technological age, the use of educational technologies in the classroom has become increasingly necessary in order to bring the students closer to the world around them, and especially in the case of teaching geography, since it is committed to the formation of citizens of the world. The main objective is to analyze the film as a didactic-pedagogical instrument for the teaching of geography. The method used is bibliographic research, and the analytical reading is the main technique of this type of research, because it is through it that one can identify the information and data contained in the selected biography, as well as verify the relationships between them, in order to analyze their consistency for use in the research. As a result of the research, educational technologies have been gaining more and more space in schools, as they work as a way to support the teaching and learning of curriculum content. The film is seen by the researched authors as an attractive didactic-pedagogical instrument for the teaching of geography, in the understanding of the nature-society relationship, significantly contributing to the teaching-learning process of geographic contents. It is concluded that its use should always have a good planning of the classes by the teachers, since through the film it is possible to arouse interest, improve participation, stimulate debate and critical reflection of students.

Keywords: Geography Teaching; Film; Didactic-pedagogical instrument

Professora titular na Universidade Estadual de Santa Cruz, Ilhéus, BA. E-mail: j.chiapetti@gmail.com

II Licenciado em Geografia pela Universidade Estadual de Santa Cruz. E-mail: gmf1027@hotmail.com 


\section{INTRODUÇÃo}

Em plena era tecnológica, o uso de tecnologias educacionais em sala de aula tem se tornado cada vez mais necessário a fim de aproximar o aluno do mundo que o cerca, de uma maneira mais atraente e prazerosa. Acredita-se que na sociedade contemporânea alunos e professores convivam diariamente, sejam em suas casas ou no ambiente escolar, com imagens, áudios e vídeos, ou seja, recursos audiovisuais dos quais o filme é parte integrante. Logo, é possível que o filme seja um instrumento auxiliar da ação educativa e do desenvolvimento da capacidade de aprendizagem dos alunos, tornando-os capazes de interpretar e compreender o cotidiano que os cerca e a realidade do mundo de maneira geral.

Nesse sentido, é evidente a necessidade da utilização de novas metodologias no domínio do ensino da Geografia, ciência que se caracteriza pelo alto grau de dinamicidade e interdisciplinaridade no seu corpo conteudista. O professor de Geografia deve ser um produtor e pesquisador de novos métodos de ensino, visando a dinamização de suas aulas para promover bons resultados na relação ensinoaprendizagem. Ou, dito de outra maneira, é preciso utilizar variadas metodologias de ensino para estimular, incentivar, atrair e até "provocar" os alunos nas aulas de Geografia, empregando instrumentos didático-pedagógicos que possam promover aprendizagem de forma atrativa.

O filme pode ser utilizado em todos os níveis do ensino, assim como, em várias outras disciplinas além da Geografia, como na História, na Literatura, na Filosofia, na Matemática, entre outras. Utilizá-lo na prática educativa de forma contextualizada pode ser algo inovador e enriquecedor e, por isso, os envolvidos no processo de ensino-aprendizagem, ou seja, professores e alunos, não podem manter-se alheios a tal instrumento, que pode Ihes aguçar curiosidade e imaginação, além de aprimorar seu senso crítico.

Diante do contexto, a questão norteadora da pesquisa propõe: o filme pode ser um instrumento didático-pedagógico atrativo para o ensino de Geografia? Para tanto, o presente trabalho tem por objetivo geral analisar o filme como instrumento didático-pedagógico no ensino de Geografia, e como objetivos específicos: discutir o uso de tecnologias educacionais na educação escolar, discorrer sobre a história da 
Geografia Escolar, discutir o uso de filmes no ensino de Geografia, e sugerir alguns filmes atrativos para o ensino de conteúdos geográficos.

E por fim, como justificativa essa pesquisa poderá contribuir com a discussão sobre tecnologias educacionais no ensino de Geografia, referindo-se especialmente ao uso do filme como instrumento didático-pedagógico para ser empregado nas aulas de Geografia.

\section{METODOLOGIA}

O desenvolvimento dessa pesquisa seguiu a metodologia de uma pesquisa bibliográfica. O fundamento da pesquisa bibliográfica é trabalhar com informações e dados secundários, coletados através de fontes bibliográficas sobre 0 tema, necessárias ao tipo da pesquisa desenvolvida. Este tipo de pesquisa se refere à investigação de um determinado tema somente através de consulta bibliográfica, ou seja, a pesquisa é elaborada a partir de material já publicado (livros, artigos científicos, documentos e outros), sem coletar dados em campo.

De acordo com Lima e Mioto (2007), a pesquisa bibliográfica é importante na produção do conhecimento científico, sendo capaz de gerar, especialmente em temas pouco explorados, interpretações que servirão de ponto de partida para outras pesquisas.

Para Gil (1994), no caso da pesquisa bibliográfica, a leitura apresenta-se como a principal técnica, pois é através dela que se podem identificar as informações e os dados contidos no material selecionado, bem como verificar as relações existentes entre eles, de modo a analisar a sua consistência.

Como procedimentos metodológicos dessa pesquisa, inicialmente foi realizado o levantamento das informações ou levantamento bibliográfico referente ao tema em questão, tais como: trabalhos acadêmicos (monografias, dissertações e teses); artigos científicos; livros técnico-científicos e seus capítulos; todos buscados na biblioteca da UESC e em acervos particulares, como também, em sites acadêmicocientíficos.

Depois de selecionada a bibliografia, fez-se a leitura criteriosa e analítica de cada uma das obras, com o intuito de buscar conhecimento para desenvolver a fundamentação teórica da pesquisa, como também, obter resposta a sua questão 
norteadora, com o alcance dos objetivos da pesquisa. Para Gil (2004, p. 68): "A finalidade da leitura analítica é a de ordenar e sumariar as informações contidas nas fontes, de forma que estas possibilitem a obtenção de respostas ao problema de pesquisa". Para tanto, os principais autores que embasaram essa pesquisa foram: Belinsk (2016), Chiofi e Oliveira (2014), Pereira (2012), Reis (2010) e Rocha; Montovani e Costa (2017).

Belinsk (2016) abarca o ensino de Geografia de qualidade e traz uma contextualização sobre os grandes períodos da história da Geografia Escolar. Com Chiofi e Oliveira (2014) foi possível traçar um breve panorama da relação entre o ensino e as tecnologias educacionais.

Por sua vez, Pereira (2012) contribui para a construção desta pesquisa no sentido de que sua obra leva à reflexão acerca das práticas didático-pedagógicas de ensino-aprendizagem do saber geográfico no século XXI, período em que se firmou a importância do aluno entender o mundo em que vive e a consciência de que deve ser um cidadão reflexivo e crítico.

Reis (2010) apresenta uma breve contextualização histórica da utilização e evolução da tecnologia pelos seres humanos a partir da sua necessidade, e aborda os conceitos de tecnologia e de tecnologia educacional. Foi fundamental para a pesquisa o artigo de Rocha; Montovani e Costa (2017), com o objetivo de compreender de que forma a utilização de filmes pode contribuir para o ensino enquanto instrumento didático-pedagógico.

Depois de lidas e relidas todas estas principais fontes bibliográficas, assim como as demais que, mesmo não sendo utilizadas como fundamentação teórica, foram necessárias no desenvolvimento da pesquisa, passou-se à sua escrita e formatação na forma deste artigo científico.

\section{O USO DE TECNOLOGIAS EDUCACIONAIS NA EDUCAÇÃO ESCOLAR}

Ao longo da sua existência o ser humano foi se apropriando dos recursos da natureza para alcançar fins específicos relata Reis (2010), que garantiram a sua sobrevivência e a manutenção da sua espécie como, por exemplo, as pedras, os ossos, os galhos e os troncos de árvores. O uso de tais recursos foi evoluindo junto 
com a história da humanidade e, à medida que evoluía, passava a descobrir novas ferramentas com os metais (cobre e ouro) (REIS, 2010).

Kenski (2008) afirma que as tecnologias são tão antigas quanto a própria espécie humana, pois, devido à "engenhosidade humana", ao longo de todos os tempos é que se chegou às mais diferenciadas tecnologias. Afinal, os elementos tecnológicos não são exclusividade da era da informatização, já que instrumentos usados pelos ancestrais também podem ser considerados como tecnologia e, como tais, se fizeram importantes para a sua sobrevivência em sua época.

Conforme Araújo et al. (2017, p. 922), não somente os equipamentos e aparelhos são tecnologia, mas sim, tudo que é produzido pela engenhosidade do cérebro humano:

Há uma perspectiva generalizada de que tecnologias são apenas equipamentos e aparelhos, mas como ela engloba a engenhosidade do cérebro humano, tudo o que se produz torna-se tecnologia. Na idade da pedra, por exemplo, para se defender de animais ferozes o homem usava armas, elementos da natureza e aos poucos foram surgindo novas tecnologias, mas não apenas para defesa e sim para dominação. A partir daí começou uma guerra pela conquista de territórios. Do osso e a madeira utilizados como armas, passou-se a fazer uso de lanças, flechas, barcos e até mesmo navios. Dessa forma, com a inovação tecnológica o homem começou uma busca incessante pelo acúmulo de riquezas.

E, nesse contexto de inovação, a partir da construção do conhecimento, o homem chegou ao domínio da escrita, o qual teve grande importância para a humanidade, pois, como afirma Fonseca Filho (2007), quando o homem começou a reunir documentos escritos rompeu com as limitações antes impostas pela transmissão oral, o que lhe permitiu avançar em diversos aspectos, inclusive, a construção de bibliotecas e a criação de arquivos deram início ao desenvolvimento de métodos de crítica, principalmente, a partir do século XVII.

No século XX foram desenvolvidos os primeiros computadores, sendo, a princípio, segundo Reis (2010, p. 4) com fins militares: "[...] para calcular as equações diferenciais que permitiam dirigir os projéteis ao alvo". Porém, para se chegar a computadores foi preciso fazer uso das descobertas teóricas que se deram ao longo dos séculos para criar ferramentas que pudessem maximizar a capacidade intelectual humana (FONSECA FILHO, 2007).

Sobre tecnologia, Abbagnano (1982) escreve que a tecnologia é o estudo dos processos técnicos de um determinado ramo de produção industrial ou de mais 
ramos. Nesse sentido, tecnologia envolve todo um conjunto de técnicas utilizadas para o desenvolvimento de ferramentas tecnológicas.

Analisando a etimologia da palavra, tem-se que:

[...] o termo tecnologia vem do grego technê (arte, ofício) e logos (estudo de) e referia-se à fixação dos termos técnicos, designando os utensílios, as máquinas, suas partes e as operações dos ofícios. Estaríamos perante uma tecnologia descritiva e enumerativa que apesar do auxílio que prestou na conquista da natureza, propiciando processos desmitológicos, de racionalização da economia e avanços da ciência em geral, foi desconsiderada em importância e prestígio social durante muitos milênios em favor do saber intelectual (ALVES, 2009, p. 18, grifos do autor).

Silva (2002, p. 1) defende que o termo tecnologia é mais bem aplicado nas engenharias e se trata de: "[...] um conjunto de conhecimentos, especialmente, princípios científicos, que se aplicam a um determinado ramo de atividade: tecnologia mecânica. Evidentemente, é dentro das áreas de engenharia que esse termo é mais aplicável, para produtos, processos e sistemas". Segundo esse mesmo autor, o uso indiscriminado do termo tecnologia, em diferentes áreas do conhecimento das ciências humanas e sociais, tem modificado o seu significado em comparação com a conceituação original, dificultando muitas vezes o seu entendimento. Ele chama de modismo a utilização dessa palavra em áreas que não têm a ver com a conceituação original, oriunda da Revolução Industrial no final do século XVIII.

Entretanto, a utilização do termo tecnologia tem sido generalizada para outras áreas do conhecimento, como por exemplo, tecnologia educacional ou tecnologia organizacional. Comumente se relacionam as tecnologias ao saber científico, como também, elas evoluem, inevitavelmente, assim como a humanidade. Sancho (1998i citado por LIMA, 2013, p. 2) considera que as tecnologias são:

[...] instrumentos técnicos ligados ao saber científico e ao serem aplicados na prática, transformamos as atividades humanas, fundamentando assim a ciência. Esses instrumentos se evoluem à medida que o tempo passa, logo chamamos de novas tecnologias os vários instrumentos criados ou modificados recentemente nos séculos XX e XXI. A expansão das tecnologias atinge a todas as esferas da sociedade, no campo social, econômico e político. Sendo assim, é imprescindível acompanharmos as evoluções tecnológicas, já que elas são instrumentos que modificam a nossa própria forma de viver.

Depois de se referir à evolução do conceito de tecnologia e, como o objeto de estudo desta pesquisa consiste em analisar o filme como um instrumento didáticopedagógico para aulas de Geografia, mas que necessita de um "equipamento 
tecnológico" para ser utilizado, faz-se imprescindível refletir sobre o que realmente pode ser chamado de tecnologia educacional.

\subsection{As tecnologias educacionais e a educação escolar}

Refletindo sobre o princípio da educação escolar e desde quando o uso de tecnologias passou a fazer parte "desse mundo", Chiofi e Oliveira (2014) ponderam que antes da Revolução Industrial a educação escolar se dava a partir da relação entre o professor e o aluno, através da oralidade, ou seja, método em que o professor somente transmitia as informações. Tal método de ensino teve grande importância para diferenciar os homens letrados daqueles que não sabiam ler e escrever, dando- Ihes a sensação de inserção na sociedade.

A Revolução Industrial também interferiu na educação escolar e no direito à educação, por causa da necessidade de se ter trabalhadores melhor preparados para o trabalho na indústria, devido à transformação da matéria prima em produtos, a partir do desenvolvimento das máquinas (FLACH, 2009).

Pode-se dizer que a evolução da tecnologia acompanhou o crescimento da população e as transformações na forma de produção. Entre os anos de 1820 e 1840 ocorreu um período de transição dos métodos de produção artesanal, cuja principal característica era a pequena demanda e a altíssima qualidade dos produtos, para a produção industrial, com maior quantidade de produtos; porém, com a fabricação sedimentada, realizada, principalmente por máquinas da época. Daí em diante, deuse início à fabricação em série; mas, com o aumento da produção o homem necessitava, cada vez mais, vender seus produtos. Então, pensou-se em inserir essa produção no mercado, focando todos os setores, inclusive, o setor da educação (FLACH, 2009; CHIOFI; OLIVEIRA, 2014).

Com relação às tecnologias educacionais, Freitas (2007) busca defini-las como sendo os materiais e equipamentos didáticos utilizados em um método de ensino, com o objetivo de estimular e aproximar o aluno do conteúdo. Como exemplo, no caso dos mapas e globos, seu uso não se trata de uma mera ilustração dos pontos geográficos, mas sim, de uma estratégia de ensino visando favorecer o processo de significação do que está sendo exposto, para aproximar o aluno do conteúdo da aula e dos livros. 
A partir dos anos 1960, passou-se a sistematizar mais a introdução da tecnologia nas escolas brasileiras. Mas, o meio educacional demonstrou grande resistência a ela, porque a proposta era de inserir cada vez mais equipamentos tecnológicos novos na sala de aula, justamente os que vinham sendo produzidos pela indústria de forma mais acelerada, refletindo um contexto político-econômico que visava à inserção do Brasil no mercado econômico mundial, como produtor e consumidor de bens, na perspectiva de um desenvolvimento associado ao capital (CHIOFI; OLIVEIRA, 2014).

Indiscutivelmente, a educação está, a partir dos anos 1990, associada a novas tecnologias, principalmente porque os jovens utilizam cada vez mais as ferramentas tecnológicas, como computadores, celulares e tabletes conectados à internet (PENHA; MELO, 2016) e essas, em suas diferentes formas de representações, possibilitam o uso de inúmeros instrumentos didático-pedagógicos na sala de aula, sobretudo no ensino de Geografia.

Nesse contexto, é preciso reconhecer que neste período técnico-científicoinformacional não se pode dissociar educação de tecnologias, como afirmam Penha e Melo (2016, p. 117):

$\mathrm{Na}$ atualidade, em que se vivencia o período técnico-científico-informacional, não tem como dissociar educação e novas tecnologias, seja no ambiente escolar (currículo formal) ou cotidianamente (currículo informal), visto que, cada vez mais cedo, os jovens vêm utilizando tecnologias. A internet, por exemplo, disponibiliza uma infinidade de informações e pode ser utilizada como recurso pedagógico no auxílio do ensinar-aprender, da construção do conhecimento [...].

A escola vai se transformando com o passar dos anos, passando por mudanças constantes quando o olhar tradicional evolui para o digital e, cada vez mais, os professores têm um papel fundamental no processo de ensino-aprendizagem, pois a tecnologia e a educação escolar andam juntas (MACHADO; LIMA, 2017). De acordo com Brasil (2010, não paginado):

[...] o profissional que atua na educação básica precisa ressignificar o trabalho com o uso das novas tecnologias, tecendo um olhar metodológico para a utilização dessa ferramenta didática no processo de ensino e aprendizagem. Ainda, as Diretrizes Curriculares da Educação Básica evidenciam a necessidade do uso da tecnologia na abordagem dos conteúdos disciplinares, afirmando que "o trabalho com as mídias tecnológicas insere diversas formas de ensinar e aprender, e valoriza o processo de produção de conhecimentos".

Inserir novas tecnologias na educação escolar, disponibilizando instrumentos didático-pedagógicos, provoca reações diversas no ambiente escolar. Alguns 
acreditam que apenas essa inserção pode resolver todos os problemas da educação e há aqueles que não creem que essa inserção consiga modificar algo e, ainda, os que acreditam nessas inserções como modificações positivas, mas têm consciência que elas por si só não sejam suficientes. Afinal, a origem das deficiências na educação escolar brasileira perpassa diversas esferas, desde a implantação da política social para a mesma (LIMA, 2013).

Moran (2007) aponta um grande desafio na utilização da tecnologia na educação escolar, dizendo que ela deve ajudar a desenvolver no aluno o gosto do aprender, mas também, que é necessário, além disso, que os professores humanizem as tecnologias educacionais, justamente para utilizá-las como instrumentos didáticopedagógicos voltados para a construção do conhecimento pelos alunos. Deve-se compreender a tecnologia em sua totalidade, assim como as suas consequências no processo de ensino-aprendizagem.

O computador é um objeto importante na vida do aluno, mas levar somente isto em consideração pode fazer com que o educador deduza que a introdução do computador na educação limita-se apenas a aprender sobre o computador e não através do computador, desprestigiando a gama de recursos que este instrumento pode nos oferecer (LIMA, 2013, p. 3).

Há que se considerar, também, alguns entraves para a utilização das tecnologias educacionais em sala de aula. Talvez, o principal esteja relacionado à realidade da escola, pois como se sabe, nesse país em que a educação é por tantas vezes sucateada, muitas escolas sequer conseguem oferecer o básico para o seu funcionamento, pois a falta de recursos financeiros ainda é realidade no Brasil, como em algumas escolas, sobretudo, em pequenas cidades ou, ainda, no meio rural desses municípios.

Outros entraves são a deficiência na formação profissional dos professores e a falta de planejamento das aulas por parte deles, os quais, pouco preparados não têm consciência da importância de uma metodologia de ensino adequada ao conteúdo, assim como, da seleção dos conteúdos a serem trabalhados em sala de aula, para que o processo ensino-aprendizagem ocorra de forma eficaz, leve e feliz. Para Beauchamp e Silva (2008, p. 17), é preciso estar atento ao sentido do uso da tecnologia e à necessidade de comprometimento deste com a formação dos cidadãos: 
cidadãos, com a gestão democrática, com o respeito à profissão do professor e com a qualidade social da educação. Sabe-se que o emprego deste ou daquele recurso tecnológico de forma isolada não é garantia de melhoria da qualidade da educação. A conjunção de diversos fatores e a inserção da tecnologia no processo pedagógico da escola e do sistema é que favorecem um processo de ensinoaprendizagem de qualidade.

Não basta ao professor o conhecimento básico na área da tecnologia, é preciso buscar soluções para ultrapassar as barreiras, o que o tornará um potencializador na sua utilização, para que assim seja capaz de proporcionar a construção do conhecimento para seus alunos, ajudando-os a se tornarem cidadãos críticos e atuantes. Como a tecnologia faz parte do dia a dia de grande parte dos alunos, esses esperam que o professor se utilize dela na escola, já que ele é o guia do processo de ensino-aprendizagem, sendo também o elo entre o aluno e a comunidade científica (MACHADO; LIMA, 2017).

Vieira (2012, p. 98) enumera algumas tecnologias educacionais à disposição dos professores, como também, presentes na vida dos alunos adolescentes e jovens: "Computadores, computadores portáteis (laptops), celulares com acesso à internet, TV digital (HD), mídias removíveis (Mp3, Mp4), câmeras digitais, DVD, Palm Top (computadores de mão), tablets".

Freitas (2007) aborda a classificação das tecnologias educacionais utilizadas em aula, dizendo que são recursos visuais, auditivos ou audiovisuais, ou seja, recursos que podem estimular o aluno por meio da percepção visual, auditiva ou ambas, concomitantemente, conforme verificamos no quadro 1.

\section{Quadro 1 - Classificação brasileira de recursos audiovisuais}

\begin{tabular}{|c|c|c|}
\hline Recursos visuais & Recursos auditivos & Recursos audiovisuais \\
\hline Álbum seriado & Aparelhos de som & Filmes \\
Cartazes & Discos & Diapositivos e diafilmes com som \\
Exposições & Citas cassete & Cinema sonoro \\
Fotografias & CDs & Televisão \\
Flanelógrafos & Rádios & Videocassete \\
Gráficos & CD-ROM & Aparelho de DVD \\
Gravuras & & Computador \\
Mapas & \\
Modelos & \\
Murais & & \\
Museus & & \\
Objetos & & \\
Quadros de giz & & \\
Quadros & & \\
Transparências & & \\
\hline
\end{tabular}

Fonte: Freitas (2007). 
Alguns desses recursos citados no quadro 1 foram criados exclusivamente para fins de ensino, ou seja, para uso didático-pedagógico com a função específica de mediar a construção do conhecimento que ocorre no ambiente escolar.

Historicamente, no Brasil, as sucessivas reformas educacionais incluem materiais didáticos inovadores, como exigências de novas filosofias e/ou metodologias de ensino, que agregam aos conceitos didáticos e pedagógicos a reformulação da prática docente. Em geral, tal reformulação prevê a adoção de novas técnicas, às quais se relacionam novos materiais e equipamentos (FREITAS, 2007, p. 22).

É importante ressaltar que a incorporação de novas tecnologias não elimina ou descarta o uso das outras antes empregadas. O professor deve fazer uso delas conforme as necessidades e a realidade em que os envolvidos no processo de ensinoaprendizagem estão inseridos.

Rocha e Bernadino (2014) argumentam que as rápidas alterações e inovações técnico-científicas afetam todos os setores da sociedade. Eles ainda escrevem que, na educação, mais precisamente na escola pública, cuja realidade dos alunos muitas vezes os distancia das demais esferas da sociedade, é preciso utilizar as tecnologias para que tenham: "Maiores possibilidades de pesquisar e interagir com diferentes espaços, pessoas, distantes ou próximas" (p. 4). Esses mesmos autores continuam escrevendo que, os alunos devem ter mais oportunidades de acesso a informações, entretenimentos, entre outros, que favoreçam suas experiências e aprendizagens, fundamentais para construir: "Um novo modelo de escola, mais agradável e significativa para toda comunidade escolar" (p. 4).

Cysneiros (1999, p. 14) enxerga nas tecnologias educacionais oportunidade de algumas melhorias para a educação, mas também menciona o perigo de acreditar cegamente no discurso dos defensores das novas tecnologias educacionais:

\footnotetext{
Nossa utopia é sempre tentar mudar a história futura para melhor, e não defendo posições tradicionalistas ou contrárias à tecnologia na educação. Vejo as novas tecnologias como mais um dos elementos que podem contribuir para melhoria de algumas atividades nas nossas salas de aula. Por outro lado, também não adoto o discurso dos defensores da nova tecnologia educacional, que mostra as mazelas das escolas (algo muito fácil de se fazer), deixando implícito que nossos professores são dinossauros avessos a mudanças. É um discurso tentando nos convencer a dar mais importância a objetos virtuais, apresentados em telinhas bidimensionais, deixando implícito que a aprendizagem com objetos concretos em tempos e espaços reais está obsoleta.
}

A escola deve assumir seu papel de espaço socializador e contribuir para que o aluno possa relacionar os saberes ali adquiridos e os demais saberes. Nesse contexto, as tecnologias de ensino são necessárias em diversos ambientes e, no espaço escolar, 
especificamente, funcionam como uma forma de alicerçar o ensino e aprendizagem dos conteúdos curriculares. Pode-se contar nas aulas com computadores, TV Pendrive, lousa digital, rádio, máquina fotográfica, telefone celular, texto, imagem e som, diversos editores de textos e gráficos, aparelhos de DVD, softwares, vídeos, documentos, enciclopédias na web, internet (ROCHA; BERNADINO, 2014).

Para Miranda (2017), especificamente, a internet é um ótimo exemplo de ferramenta que permite aos seus usuários trocar ideias e compartilhar pesquisas. As comunidades virtuais são capazes de abrir uma nova dimensão ao exercício intelectual, ajudando a desenvolver a rapidez de raciocínio e também o trabalho em equipe. Além disso, existe a possibilidade de criar um espaço de aprendizagem resultante da busca e da troca de informações.

\subsection{Ciência geográfica e Geografia Escolar}

Parte-se do pressuposto de que é preciso inserir propostas inovadoras na prática docente da Geografia, que vão além de quadro, giz e livro didático e que, ao mesmo tempo, sejam dotadas de conteúdo para proporcionar a possibilidade de aprendizagem de forma lúdica e mais agradável para os alunos, consequentemente, uma maneira de despertar mais interesse pelos conteúdos geográficos. Mas, é importante concordar com Belinsk (2016, p. 19), quando diz que o ensino de Geografia de qualidade: "Perpassa não apenas pelo emprego de metodologias criativas, mas também, pela compreensão das finalidades da disciplina no âmbito escolar".

Por causa da expansão do capitalismo, a partir do século XVIII, houve uma aceleração no desenvolvimento da Geografia e também das demais ciências. Pode-se dizer que, até então a visão geográfica se voltava à observação empírica das paisagens (KAERCHER, 1998).

Belinsk (2016) considera importante caracterizar brevemente os três grandes períodos da história da Geografia Escolar: Geografia Clássica (do século XVI ao início do século XX), Geografia Moderna (entre as décadas de 1920 e 1970) e Geografia Crítica (a partir de 1970). Sabe-se que há outras periodizações sugeridas por outros autores, no entanto, esse texto refere-se a essa periodização. 
A Geografia Clássica tem como destaque a tentativa de difundir conhecimentos adquiridos desde a antiguidade clássica; não obstante, a Geografia não se configurava como disciplina autônoma, mas os conhecimentos geográficos estavam presentes em outras disciplinas. Além de que, grande parte do material utilizado nas escolas brasileiras até 1880 vinha de escolas estrangeiras, tendo primeiramente sido levado para Portugal e adaptado para o Brasil. Quem lecionava Geografia eram advogados, engenheiros, médicos, entre outros, pois até 1930 no Brasil não havia nenhuma instituição superior que formasse professores especificamente de Geografia (BELINSK, 2016).

Talvez por isso, havia uma grande dependência dos livros didáticos para dar aulas e os métodos baseavam-se basicamente na memorização das informações. Era comum a utilização do método dialogístico, que consistia na pergunta e resposta de maneira decorada. Tais perguntas versavam sobre conceitos relacionados ao aspecto físico e natural, nome de países, Estados, capitais, rios, extensão territorial, dados demográficos, entre outros. Era valorizado como bom aluno aquele que conseguia memorizar esses dados.

Só após a segunda metade do século XIX a Geografia se estabeleceu como ciência autônoma, recebendo em sua raiz a herança do positivismo clássico, que trouxe à tona duas correntes ideológicas divergentes entre si: o determinismo e o possibilismo (KAERCHER, 1998).

Apenas no início do século XX foram se firmando algumas transformações na Geografia Escolar, marcadas pela inserção do fazer científico na Geografia Moderna, visto que até então a disciplina estava longe dos debates científicos da época. A criação do primeiro curso superior em Geografia e História no Brasil, em São Paulo, no ano de 1934, contribuindo para a ampliação da discussão científica, pode ser citada como exemplo. E, ainda sob a influência da Geografia francesa o enfoque era essencialmente regional e o estudo de uma região previa quase sempre algumas etapas metodológicas: descrição da parte física, com exame do relevo, clima, vegetação e hidrografia, análise de povoamento, etnia, cultura e divisão políticoadministrativa (BELISNK, 2016).

Somente a partir de 1937 se começou uma simbólica ampliação da quantidade de livros didáticos elaborados por autores brasileiros, o que passou a trazer mais informações referentes ao território brasileiro e mudança na proposta de apresentação dos conteúdos, quando o método dialogístico foi sendo substituído, 
principalmente, pelas descrições de conceitos e características, além da inserção, com o passar do tempo, de imagens (mapas, gravuras, desenhos esquemáticos) como recurso didático auxiliar (BELINSK, 2016).

No decorrer da Segunda Guerra Mundial, os estudos de Geografia foram recebendo grandes impulsos a partir dos avanços tecnológicos. Assim, após esta Guerra, a internacionalização da economia e a progressiva acentuação da crise do capitalismo contribuíram para o surgimento do que se considera como uma nova maneira de se fazer Geografia, com a crítica alicerçada a produções filosóficas e com o instrumental teórico-metodológico permitindo a compreensão das inúmeras transformações que envolvem as problemáticas do mundo (VESENTINI, 2009). Assim, a disciplina de Geografia deixou de ser fundamentalmente chauvinista e voltada diretamente para a memorização, passando a se fazer uma Geografia Crítica (KAERCHER, 1998; VESENTINI, 2009).

Conforme Pereira (2012), depois da Segunda Guerra Mundial, o mundo revelou um acelerado processo de transformação em inúmeros setores da sociedade e a educação é uma das áreas que mais vem sofrendo mudanças, justamente por conta de uma série de desafios que é imposta aos professores, como por exemplo, o professor precisa mediar os saberes formais que contemplem várias capacidades e habilidades para que o aluno possa se inserir no denominado mundo do trabalho e, respectivamente, seja capaz de adquirir conhecimentos que o transforme em um cidadão pleno.

No período da ditadura militar brasileira (1964-1985), as disciplinas de História e Geografia foram unidas e denominadas de "Estudo Sociais" e, assim, seguiu-se um modelo tecnicista, deixando as humanidades, propositalmente, para segundo plano, revogando sua autonomia e diminuindo a carga horária. Kaercher (1998) ressal ta que somente há pouco tempo atrás se rompeu com a Geografia Tradicional e despolitizada, a partir da democratização da sociedade e da escola.

Cavalcanti (2002) diz que é perceptível o movimento de renovação do ensino nas escolas brasileiras, fazendo uso de novas metodologias, projetando outras formas de aprender a ensinar, como, por exemplo, a utilização da música, do filme, do jornal, da revista.

É preciso reconhecer que as transformações cada vez maiores nas comunicações, nas informações e nas tecnologias demandam o domínio de novas linguagens e técnicas para a vida em sociedade, o que termina tornando explícito que 
o ensino pautado exclusivamente na memorização não fornece as condições necessárias para enfrentar os desafios existentes. $O$ que não significa que determinados conhecimentos não eram importantes, mas sim, a necessidade de uma relação com a sociedade e com o cotidiano dos alunos. Por esse motivo houve uma ampliação no que se refere à busca de alternativas ao ensino de Geografia, tanto a partir da inserção de temas mais próximos à realidade dos alunos, quanto pela discussão acerca de novas propostas didático-metodológicas (BELINSK, 2016).

Tomita (2006, p. 34) escreve sobre o sentimento dos alunos em aulas de Geografia que não interessam:

[...] a defasagem e a fragilidade na metodologia acabam provocando, no aluno, sentimento de desprezo, tédio e antipatia pela disciplina, pela aula e pelo professor, fazendo-o perder o entusiasmo, não reconhecendo o verdadeiro sentido da função do processo de ensino-aprendizagem, no qual poderia haver mais compreensão e o despertar do verdadeiro sentido do ensino de Geografia.

Contudo, ao se utilizar recursos, materiais ou equipamentos didáticos na sala de aula, é importante a realização do planejamento didático, cabendo ao professor a sua elaboração e implementação. Entretanto, Freitas (2007, p. 15) diz que:

Em tempos de gestão democrática de educação, para a inclusão escolar e social, sugere-se a participação de todos, em todas as instâncias e em todos os espaços da escola. Inclui-se aí a efetiva participação dos funcionários nas instâncias pedagógicas, como gestores e educadores que reúnem as habilidades necessárias ao desenvolvimento de ações que envolvam o apoio didático às aulas planejadas pela equipe docente.

O planejamento discutido por todos envolvidos no processo de ensinoaprendizagem é fundamental para evitar, por exemplo, o emprego de atividades soltas em que os conteúdos são apresentados de maneira aleatória, sem relacioná-los aos problemas da vida que os alunos precisam conhecer.

\subsection{Ensino de Geografia e tecnologias educacionais}

De acordo com Vesentini (2009, p. 22), é preciso buscar o desenvolvimento do ensino-aprendizagem da Geografia de uma maneira lúdica e atrativa, para que os alunos compreendam o mundo em constante transformação e, assim, seja possível compreender o mundo em que vivem: "Da escala local até a planetária, dos problemas ambientais até os econômico-culturais".

No caso específico do ensino de Geografia, é possível utilizar inúmeras tecnologias educacionais para tanto, pois conforme Voigt; Giordanni e Bezzi (2010), a 
Geografia enquanto disciplina utiliza diversos instrumentos tecnológicos para a compreensão da interface natureza-sociedade, citando o filme como um deles. Tais tecnologias contribuem para o processo de ensino-aprendizagem, pois promovem mais possibilidade de interatividade entre os alunos e os conteúdos geográficos.

Segundo Belinski (2016), entre os vários instrumentos ou recursos que podem ser usados nas aulas de Geografia é possível citar, além dos populares livros didáticos e paradidáticos, mapas, fotografias áreas, imagens de satélites, literatura, músicas, poemas, fotografias, videoclipes, jogos, jogos eletrônicos, jornais, revistas, filmes e documentários, consistindo, assim, numa grande abrangência de tipos de instrumentos didático-pedagógicos, tecnológicos ou não.

Ressalta-se, entretanto que, corroborando com Luz (2016), para fazer uso desses instrumentos o ideal é que se tenha em mente que apenas usá-los não é o suficiente, pois para se obter êxito são necessários: adequação aos objetivos; conteúdo e grau de desenvolvimento; interesse e necessidade dos alunos; adequação às habilidades cognitivas; adequação às habilidades afetivas; adequação às habilidades psicomotoras; simplicidade; baixo custo; manipulação acessível; qualidade e criatividade.

$\mathrm{Na}$ intensa corrida para encontrar as melhores formas de alcançar os objetivos de suas disciplinas, de acordo com Rocha; Montovani e Costa (2017, p. 160), os professores têm que utilizar diversas formas de linguagem:

[...] reconhecer a importância das diversas linguagens que constroem o mundo das informações é o primeiro passo para que o educador contribua com uma formação significativa que permita aos alunos autonomia e condições a fim de transformar a sua realidade. Uma das preocupações do professor de Geografia é pensar quais práticas pedagógicas devem ser adotadas e como alterá-las de modo que a abordagem de temas tão variados e complexos seja estimulante e interessante.

Campos (2006) faz uma análise, especificamente, acerca da utilização de recursos audiovisuais ou tecnologias educacionais nas aulas de Geografia, discorrendo sobre a indústria cinematográfica e enumerando algumas vantagens e desvantagens do seu uso, tanto do ensino fundamental quanto do ensino médio. Contudo, para ele, não há grandes novidades na utilização dessas tecnologias como instrumentos didático-pedagógicos; afinal, os professores há algum tempo já utilizam: "Músicas, slides em power point, fotografias, poesias e filmes, para auxiliar na compreensão do conteúdo" (CAMPOS, 2006, p. 1, grifos do autor). 
No caso específico do cinema, trata-se de uma arte com a vantagem de poder ser utilizada de diversas formas, inclusive, por outras artes, conseguindo se comunicar com profundidade e envolvimento. O cinema tem o poder de exprimir, de forma direta ou não, os valores do roteirista, do diretor, da própria sociedade e do momento histórico no qual o filme se passa ou foi realizado, como também, a realidade atual. Isso é muito importante para o ensino de Geografia, quando se quer alunos conscientes, críticos e participantes da produção do espaço geográfico. Sobre filme, especialmente no ensino de Geografia, será tratado no item que segue.

\section{OS FILMES NO ENSINO DE GEOGRAFIA}

A partir das muitas transformações na dinâmica mundial e os seus numerosos reflexos sobre a ciência geográfica, com inúmeros avanços e retrocessos no Brasil, a utilização de novas tecnologias como instrumentos didático-pedagógicos foi se tornando necessária e inevitável para o processo de ensino-aprendizagem geográfico (PEREIRA, 2012). Nesse contexto, o filme desponta como uma das tecnologias capazes de contribuir de forma positiva para o enriquecimento das aulas de Geografia, visto que proporciona aos alunos a inserção em aulas mais atrativas, interativas e dinâmicas.

A inclusão de novas tecnologias em aulas de Geografia auxilia na construção do conhecimento geográfico, já que possibilita aos alunos a compreensão dos problemas mundiais atuais e a construção da cidadania. Miranda (2017, p. 1) chama a atenção para o fato de que a função do professor de mediador do conhecimento permanece, mesmo com a aplicação de tecnologias educacionais:

As novas tecnologias podem e devem modificar a estrutura da aula, tornando-a mais dinâmica e, por vezes, substituir o livro didático. Mesmo frente a tudo isso, o professor não perde sua função; continua dirigindo o processo de aprendizagem, mas com outra postura, atuando como provocador ou mediador na construção do aprendizado.

A participação do professor é fundamental nesse processo de utilizar novas tecnologias, porque além de ter essa função de mediar a construção da aprendizagem, ele tem o "poder" de criar possibilidades. Por exemplo, quando um professor resolve utilizar filme para enriquecer suas aulas, é preciso que tenha um objetivo didático bem definido, saber o porquê da sua exibição, como também, é preciso criar critérios para a escolha de um título adequado, considerando a riqueza 
de oportunidades que esta tecnologia pode proporcionar; além de pensar sobre o tema proposto e a metodologia que será utilizada, ou seja, é necessário o planejamento de ensino adequado ao uso desse tipo de instrumento didáticopedagógico.

Então, o professor deve planejar tudo, desde a escolha do título do filme a ser exibido até as reflexões que ele provocará, além da forma como será organizada sua exposição, as atividades e avaliações, posteriormente. Em seu planejamento deverá levar em conta alguns questionamentos, tais como: é necessário que os alunos tenham conhecimentos prévios para compreender o conteúdo abordado? O tempo da aula será suficiente para a exibição? Caso não seja, qual o tempo disponibilizado? Quantas aulas serão necessárias? Será exibido todo o filme de uma vez? Será necessário negociar com outros professores para utilizar os horários de suas aulas? Quando findar a exibição, quais as discussões que deverão ser levantadas e de que forma? Como será a avaliação da aprendizagem, poderá acontecer a partir de questionário impresso, debate, ou grupos de discussão? Este questionamento pode contribuir no sentido de auxiliar o professor no momento de reflexão, de pensar o uso do filme em suas aulas de Geografia.

Coelho e Viana (2011) ressaltam que quando o professor consegue fazer a associação entre cinema e ensino tem grande chance de obter mais êxito no processo de ensino-aprendizagem do conteúdo a ser trabalhado, porque a linguagem do cinema é fascinante e é capaz de reunir ao mesmo tempo, questões políticas, econômicas, sociais e, até mesmo, existenciais. Logo, os filmes devem ser selecionados a partir da articulação dos conteúdos e conceitos já trabalhados, tendo em mente também o conjunto de objetivos e metas que se deseja alcançar na disciplina. Ainda para Coelho e Viana (2011, p. 92): "Certamente não serão encontrados filmes próprios para todos os conteúdos, tendo de haver conexão do conteúdo do filme a ser trabalhado com a disciplina lecionada".

De acordo com Teixeira (2006) muitas são as possíveis formas de uso de filmes no contexto escolar. Cabe ao professor encontrar sua melhor maneira de aplicabilidade e, também, decidir a forma que irá explorar o conteúdo a ser estudado. É preciso lembrar que o uso de filmes pode possibilitar a ampliação do universo de conteúdos, visto que extrapolam os conhecimentos científicos e valores sociais. Tratase de uma atividade multidisciplinar e o professor precisa ter consciência do potencial dos filmes enquanto instrumento didático-pedagógico e de tudo o que é possível levar 
para além da escola: "[...] ver filmes, discuti-los, interpretá-los é uma via para ultrapassar as nossas arraigadas posturas etnocêntricas e avaliações preconceituosas, construindo um conhecimento descentrado e escapando às posturas 'naturalizantes' do senso comum" (TEIXEIRA, 2006, p. 8).

Alencar (2007, p. 137) escreve que muitos estudiosos defendem que desde 0 princípio das primeiras produções cinematográficas já se considerava o cinema como um valioso instrumento de educação e de instrução:

O cinema possibilita o encontro entre pessoas, amplia o mundo de cada um, mostra na tela o que é familiar e o que é desconhecido e estimula o aprender. Penso que o cinema aguça a percepção e torna mais ágil o raciocínio na medida em que, para entendermos o conteúdo de um filme, precisamos concatenar todos os recursos da linguagem fílmica, utilizados no desenrolar do espetáculo e que evoluem com rapidez.

É importante ressaltar os inúmeros benefícios da utilização dos filmes para a compreensão de outras culturas, mas também, é preciso estar em alerta para a necessidade de questionamentos e análise crítica em sala de aula, pois, segundo Napolitano (2013), ao usar o cinema nas aulas de Geografia, ele se torna um interessante instrumento didático-pedagógico que ajudará o aluno no acréscimo de diversas habilidades, entre elas o desenvolvimento da capacidade crítica e sociocultural. Assim, o uso de filmes pode auxiliar na compreensão de culturas exóticas e lugares distantes, bem como, da sociedade e seus costumes locais vivenciados pelos alunos, pois geralmente os autores e roteiristas se inspiram na realidade para realizar sua ficção. Ainda segundo Napolitano (2013), um grande erro seria aceitar o filme sem questionamentos e análise crítica, pois seria uma grande armadilha ao consumir as representações ideológicas "dos outros" sem fazer uma crítica séria, assim como, simplificar culturas e espacialidades únicas e complexas.

Diante das tantas possibilidades ofertadas pela utilização de filmes nas aulas, é importante relembrar o papel fundamental do ensino de Geografia no desenvolvimento dos indivíduos em sua totalidade, o que reforça a sua necessidade em modificar-se constantemente, conforme as transformações sociais, seguindo inevitavelmente todas as influências do desenvolvimento tecnológico e do alcance da mídia no mundo globalizado.

Uma excelente forma de fazer e aprender a ensinar Geografia é, para Pereira (2012), através de metodologias que favorecem o uso de filmes, músicas e até mesmo de jogos eletrônicos, pois mesmo fazendo parte do cotidiano de crianças e adolescentes, no ambiente educacional ainda estão pouco presentes e podem ser 
úteis para trabalhar diversos conteúdos geográficos. As escolas terminam sendo desafiadas pelas tecnologias educacionais a deixarem o ensino tradicional, cujos professores são o centro, para aderir a uma aprendizagem mais atrativa, participativa e integrada, que tem vínculos presenciais e virtuais.

Barbosa (2011) diz que é importante refletir a respeito dos "filtros" necessários para uma leitura crítica de um filme a partir de um ponto de vista geográfico, destacando a autenticidade das paisagens exibidas, o etnocentrismo e os arquétipos de figuração e a subjetividade do autor na narração e na escolha dos enquadramentos do espaço representado. Atentos a esses cuidados, dificilmente haverá equívocos na utilização de determinados filmes nas aulas de Geografia, especialmente quando o professor tiver a intenção de ilustrar o tempo históricocultural descrito e a paisagem apresentada na exibição.

Não se pode negar que o trabalho com filmes no ensino de Geografia não é algo tão simples, pois não é apenas os indicar e levantar o debate sobre eles ou as questões que envolvem ou, ainda, exibi-los na sala de aula e pedir que os alunos comentem algo sobre eles. Ao contrário, há bastante complexidade nesse processo, sendo preciso que o professor exercite as suas habilidades de reflexão, de interpretação e de interação com os alunos. O professor precisa estudar antes o filme que vai trabalhar com seus alunos - pesquisar, ler críticas, compreender quando e onde se passa a história contada, contextualizá-lo no tempo e espaço - para depois poder incentivá-los a fazer análises, sempre contextualizando com o que quer que aprendam, como também, o professor deve interromper a sua exibição, periodicamente, para promover discussões, sempre atento à faixa etária e maturidade desses alunos.

É necessário que se compreenda que a linguagem do cinema é dotada de símbolos e de significados para que os seus espectadores os desvendem, nesse caso os alunos. Todo filme tem um significado cultural (ou até mais de um deles), o qual se constitui no contexto em que é produzido, pois não se trata de um evento cultural autônomo, já que ganha sentido sempre a partir de alguns valores, mitos, crenças e práticas sociais das diferentes culturas, narrativas orais, escritas ou audiovisuais (DUARTE, 2002).

É fundamental para o professor que associa ensino e cinema, que tenha consciência do fascínio que os filmes exercem a partir de sua linguagem e que são capazes de reunir questões de ordem social, política econômica e existencial. Nesse 
contexto, o filme pode contribuir como um atrativo para as aulas de Geografia, permitindo a compreensão por parte dos professores e alunos, a respeito de como diferentes sociedades educam/formam as suas novas gerações. "É sempre um mundo novo, construído na e pela linguagem cinematográfica, que se abre para nós" (DUARTE, 2002, p. 106).

Cysneiros (1999, p. 22) alerta sobre um aspecto que tem tendência a passar despercebido, que é o caráter inicial dramático da realidade mediada pelo cinema:

\begin{abstract}
Nos primeiros anos do cinema, por exemplo, as plateias em salas escuras tinham medo de cenas de trens que se aproximavam do espectador (confusão entre percepção ordinária e mediada). Ainda hoje, depois de quase meio século, a TV ainda goza do charme dramático da novidade, ao realçar formas e alterar perspectivas de rostos e de outros detalhes corporais; ao criar efeitos e modificar tempos e espaços de objetos apreendidos por lentes e manipulados depois em laboratório, mostrando-os repetidamente, descobrindo ou inventando novas realidades.
\end{abstract}

É importante que na utilização de filmes nas aulas de Geografia o professor possa considerar o seu objeto de estudo, que é o espaço geográfico, o qual pode proporcionar elementos para se compreender, numa realidade mais ampla e global, os fenômenos em relação àqueles que atuam localmente. Nesse sentido, Callai (2009) sugere que é possível analisar o espaço geográfico em sua estrutura e em sua formação, mas, muitas vezes, o ensino de Geografia se restringe ao estudo da organização espacial atual, não valorizando uma compreensão que passa pela historicidade da formação espacial. Para que seja possível entender a trajetória de construção do objeto de estudo da Geografia é importante ter como foco as relações entre os fenômenos e buscar as justificativas das coisas naquilo que não é aparente na paisagem.

Considerando que as práticas sociais dos diferentes grupos ou sociedade é que produzem o próprio espaço geográfico, é aí que a diversidade de culturas está representada e que não se pode ignorar; nesse sentido, o debate em sala de aula a partir do uso de filmes será enriquecedor para o aprendizado geográfico.

No Quadro 2 seguem algumas sugestões de filmes de ficção científica e documentários capazes de serem trabalhados no ensino de Geografia tanto nos aspectos físicos quanto humanos, tornando as aulas mais atrativas. Buscou-se enumerar alguns títulos que podem ser utilizados como fontes de conhecimento, informação e cultura, como também incentivo à reflexão crítica dos professores e alunos, sendo valorosos instrumentos didático-pedagógicos no processo de ensino- 
aprendizagem de determinados conteúdos geográficos, quebrando a rotina de aulas expositivas.

Quadro 2 - Sugestões de alguns filmes atrativos para se ensinar Geografia

\begin{tabular}{|c|c|c|c|c|}
\hline N. & Título & $\begin{array}{l}\text { Ano - } \\
\text { Origem }\end{array}$ & Direção & Temas abordados \\
\hline 01 & $\begin{array}{l}\text { Os Lobos Nunca } \\
\text { Choram }\end{array}$ & $1984-E U A$ & Carral Ballard & Biomas, climatologia \\
\hline 02 & Twister & 1996 - EUA & Jan de Bont & Tornados, mudanças climáticas \\
\hline 03 & Volcano: a Fúria & 1997 - EUA & Mick Jackson & Terremoto, vulcanismo \\
\hline 04 & O Inferno de Dante & 1997 - EUA & Roger Donaldson & Vulcanismo \\
\hline 05 & Sete Anos no Tibet & 1997 - EUA & Jan Jacques Annaud & Formas de relevo \\
\hline 06 & A Era do Gelo & 2002 - EUA & $\begin{array}{l}\text { Carlos Saldanha e } \\
\text { Chris Wedge }\end{array}$ & Eras geológicas \\
\hline 07 & $\begin{array}{l}\text { O Núcleo: Missão ao } \\
\text { Centro da Terra }\end{array}$ & $\begin{array}{l}2003 \text { - EUA } \\
\text { e Canadá }\end{array}$ & Jon Amiel & $\begin{array}{c}\text { Movimento de rotação e translação } \\
\text { da terra }\end{array}$ \\
\hline 08 & $\begin{array}{l}\text { O Dia Depois do } \\
\text { Amanhã }\end{array}$ & 2004 - EUA & Roland Emmerich & Mudanças climáticas \\
\hline 09 & O Terminal & $2004-E U A$ & Steven Spielberg & $\begin{array}{l}\text { Migração no mundo, conflitos, } \\
\text { refugiados }\end{array}$ \\
\hline 10 & Casa de Areia & $\begin{array}{l}2005- \\
\text { Brasil }\end{array}$ & $\begin{array}{l}\text { Andrucha } \\
\text { Waddington }\end{array}$ & $\begin{array}{l}\text { Paisagens naturais, } \\
\text { biomas, climas }\end{array}$ \\
\hline 11 & $\begin{array}{l}\text { Uma Verdade } \\
\text { Inconveniente }\end{array}$ & $2006-E U A$ & Davis Guggenheim & Aquecimento global \\
\hline 12 & Os Sem Floresta & 2006 - EUA & $\begin{array}{c}\text { Tim Johnson, Karey } \\
\text { Kirkptrick }\end{array}$ & $\begin{array}{l}\text { Meio ambiente, } \\
\text { consumismo }\end{array}$ \\
\hline 13 & $\begin{array}{l}\text { O Mundo Segundo a } \\
\text { Monsanto }\end{array}$ & $\begin{array}{l}2008- \\
\text { França }\end{array}$ & $\begin{array}{l}\text { Marie-Monique } \\
\text { Robin }\end{array}$ & $\begin{array}{l}\text { Organismos geneticamente } \\
\text { modificados (OGM) }\end{array}$ \\
\hline 14 & Wall - E & 2008 - EUA & Andrew Stanton & Impactos ambientais, lixo (resíduos) \\
\hline 15 & Comida S/A & 2008 - EUA & Robert Kenne & Produção industrial de alimentos \\
\hline 16 & $\begin{array}{c}\text { Entre Rios: a } \\
\text { Urbanização de São } \\
\text { Paulo }\end{array}$ & $\begin{array}{l}2009- \\
\text { Brasil }\end{array}$ & Caio Ferraz & Urbanização, hidrografia \\
\hline 17 & Home & $\begin{array}{l}2009 \text { - } \\
\text { França }\end{array}$ & $\begin{array}{l}\text { Yann Arthus- } \\
\text { Bertrand }\end{array}$ & Impactos ambientais \\
\hline 18 & $\begin{array}{c}\text { Comprar, Jogar Fora, } \\
\text { Comprar: a História da } \\
\text { Obsolescência } \\
\text { Programada }\end{array}$ & $\begin{array}{l}2010- \\
\text { Espanha }\end{array}$ & Cosima Dannoritzer & $\begin{array}{l}\text { Indústria, consumo, capitalismo, } \\
\text { recursos naturais, resíduos sólidos }\end{array}$ \\
\hline 19 & Himalaia & $\begin{array}{l}2015- \\
\text { Coreia do } \\
\text { Sul }\end{array}$ & Lee Seok-honn & Formas de relevo \\
\hline 20 & $\begin{array}{l}\text { Terremoto: a Falha de } \\
\text { San Andreas }\end{array}$ & 2015 - EUA & Brad Peyton & Movimento de placas tectônicas \\
\hline
\end{tabular}

Fonte: organização dos autores.

Notem-se no Quadro 2 que são citados filmes que remetem aos aspectos físicos da Geografia, como vulcanismo, placas tectônicas, mudanças climáticas, relevo, degradação ambiental, aquecimento global; mas também há aqueles que 
abordam as questões humanas, políticas, culturais e econômicas, todos igualmente importantes e necessários no aprendizado geográfico. Os temas são atuais e interessantes, podendo facilmente atrair curiosidade e atenção, facilitando a aprendizagem.

Vale ressaltar que é necessário o professor explorar o conteúdo de cada um desses filmes realizando analogias com os conteúdos geográficos que vai trabalhar com os alunos. Outra recomendação é que o professor ao aplicar essa metodologia de ensino o faça a partir de reflexão e contextualização histórica e espacial de cada filme, para que os alunos os compreendam e possam se ater aos conteúdos geográficos que estão sendo discutidos.

E, por fim, a maior parte dos filmes indicados foi produzida nos Estados Unidos; porém, a quantidade e qualidade de filmes brasileiros realizados nos últimos anos também é crescente, principalmente de temas voltados aos conflitos urbanos e às questões ambientais. Baseado nisto termina-se este texto com um questionamento: o que se pode pensar sobre a realidade do mundo em que se vive ou sobre o mundo que se está produzindo já que a arte, nesse caso o cinema, quase sempre está na vanguarda da ciência?

\section{CONSIDERAÇÕES FINAIS}

Sabe-se que a educação escolar é um desafio cotidiano para todos os sujeitos envolvidos, cabendo aos professores despertar o interesse do aluno, não apenas pelo conteúdo, mas também, para a vida. Não que o professor tenha que fazer tudo para chamar a atenção do aluno e convencê-lo de que é preciso estudar; embora, infelizmente, em muitos casos seja essa a realidade.

Não é fácil a missão do professor e de todos envolvidos no processo de educação, sobretudo, considerando a realidade do Brasil, um País em que a educação é tratada como um negócio ou como um custo e não como investimento para melhoria da qualidade de vida da população. A educação, principalmente, a pública está longe de se aproximar do seu ideal. A sociedade vive realidades diferentes e cada escola tem sua realidade e dificuldades, assim como, cada professor tem sua vivência, cada aluno tem também sua história... e no processo de ensinoaprendizagem nada pode ser desprezado. 
Diante das muitas tecnologias educacionais disponíveis no mundo moderno, seria inviável não lançar mão delas, já que pode vir a contribuir para a qualidade do ensino escolar e, consequentemente, da construção do conhecimento. Na era da tecnologia, boa parte dos alunos tem contato com a internet, celular, computador, aparelho de TV, pendrive, entre outros, de forma que é possível utilizar esses instrumentos didático-pedagógicos a favor da aprendizagem. $E$ assim, a partir do envolvimento destes nos objetivos educacionais, possibilitar o desenvolvimento de valores e atitudes que contribuam para a reflexão e o entendimento dos alunos acerca da realidade do cotidiano e do mundo.

Nesse contexto, conclui-se que os filmes devem ser usados como instrumentos didático-pedagógicos atrativos na sala de aula, porque a linguagem cinematográfica pode alcançar a todos envolvidos, com sua excelente capacidade de comunicação. Através deles é possível despertar o interesse, melhorar a participação, estimular o debate e a reflexão crítica dos alunos. Eles também podem transmitir mensagens capazes de traduzir valores sociais, culturais, sociais e ideológicos, mas devem ser contextualizados quanto ao tempo e espaço. Cabe ao professor "saber como tirar maior proveito" dessa tecnologia educacional, planejando previamente suas aulas, instruindo os alunos a refletir, incitando à discussão, pensando na melhor estratégia para ampliar o diálogo e o aprendizado em torno do conteúdo estudado.

No caso específico do ensino de Geografia, pode-se utilizar o filme com o intuito de estimular questionamentos que abordem questões sociais, culturais, ambientais (que englobem, por exemplo, questões sobre a importância da conservação das nascentes dos rios, degradação do meio ambiente, poluição, entre outros), políticas e, até mesmo, econômicas, sempre buscando associação com conteúdos geográficos que se quer trabalhar.

\section{REFERÊNCIAS}

ABBAGNANO, N. Dicionário de filosofia. Tradução de Alfredo Bosi. 4. ed. São Paulo: Martins Fontes, 2000.

ALENCAR, S. E. P. O cinema na sala de aula: uma aprendizagem dialógica da disciplina história. 2007.104 f. Dissertação (Mestrado em Educação) - Universidade Federal do Ceará (UFC), Fortaleza, 2007. 
ALVES, T. A. da S. Tecnologias de Informação e Comunicação (TIC) nas escolas: da idealização à realidade. Lisboa, Portugal. 2009. Dissertação (Mestrado em Ciências da Educação) - Universidade Lusófona de Humanidades e Tecnologias, Lisboa, 2009. Disponível em: http://recil.ulusofona.pt/handle/10437/1156. Acesso em: 23 set. 2018.

ARAUJO, S. P. de; et al. Tecnologia na educação: contexto histórico, papel e diversidade. In: IV JORNADA DE DIDÁTICA; III SEMINÁRIO DE PESQUISA DO CEMAD, 2017, Londrina, PR. Anais... Londrina, PR: Universidade Estadual de Londrina (UEL), Londrina, PR, 2013. Disponível em: http://www.uel.br/eventos/jornadadidatica/pages/2017---anais-da-ivjornada-de-didatica-docencia-na-contemporaneidade-e-iii-seminario-de-pesquisa-docemad.php. Acesso em: 23 out. 2018.

BARBOSA, J. L. Geografia e cinema: em busca de aproximações e do inesperado. In: CARLOS, A. F. A. et al. (Orgs.). A Geografia na sala de aula. São Paulo: Contexto, 1999. p. 109-133. 144 p.

BEAUCHAMP, J.; SILVA, J. C. da (Org.). Guia de tecnologias educacionais. Brasília: Ministério da Educação; Secretaria de Educação Básica, 2008. 93 p.

BELINSKI, P. Encaminhamentos metodológicos para o ensino de Geografia. Curitiba: InterSaberes, 2016. 249 p.

BRASIL. Ministério da Educação e Cultura. Conselho Nacional de Educação. Diretrizes Curriculares Nacionais Gerais para Educação Básica. Brasília: MEC/CNE, 2010.

CALLAI, H. C. Estudar o lugar para compreender o mundo. In: CASTROGIOVANNI, A. C. (Org.). Ensino de Geografia: prática e textualização no cotidiano. 7. ed. Porto Alegre: Mediação, 2009. p. 83-131. 171 p.

CAMPOS, R. R. Cinema, Geografia e sala de aula. Estudos Geográficos, Rio Claro, SP, v. 4, n. 1, p. 22-33, $2006 . \quad$ Disponível em: https://www.periodicos.rc.biblioteca.unesp.br/index.php/estgeo/article/view/216/177. Acesso em: 25 set. 2018.

CAVALCANTI, L. de S. Geografia e práticas de ensino. Goiânia: Alternativa, 2002.

CHIOFI, L. C.; OLIVEIRA, M. R. F. de. O uso das tecnologias educacionais como ferramentas didáticas no processo de ensino e aprendizagem. In: PARANÁ. Governo do Estado.

Os desafios da escola pública paranaense na perspectiva do professor PDE. 2014. Disponível em: http://www.diaadiaeducacao.pr.gov.br/portals/cadernospde/pdebusca/producoes_pde/201 4/2014_uel_gestao_pdp_luiz_carlos_chiofi.pdf. Acesso em: 12 out. 2018.

COELHO, R. M. de F.; VIANA, M. da C. V. A utilização de filmes em sala de aula: um breve estudo no instituto de ciências exatas e biológicas da UFOP. Revista da Educação Matemática da UFOP, Ouro Preto, MG, v. 1, 2011. Disponível em: http://www.pucrs.br/ciencias/viali/tic_literatura/filmes/C13.pdf. Acesso em: 29 out. 2018. 
CYSNEIROS, P. G. Novas tecnologias na sala de aula: melhoria do ensino ou inovação conservadora? Informática Educativa, Porto Alegre, v. 12, n. 1, 1999, p. 11-24.

DUARTE, R. Cinema \& Educação. Belo Horizonte: Autêntica, 2002.

FLACH, S. F. O direito à educação e sua relação com a ampliação da escolaridade obrigatória no Brasil. Ensaio: avaliação de políticas públicas educacionais, Rio de Janeiro, v. 17 , n. 64 , p. 495-520, jul./set. 2009.

FONSECA FILHO, C. História da computação - recurso eletrônico: o caminho do pensamento e da tecnologia. Porto Alegre: EDIPUCRS, 2007. 205 p.

FREITAS, O. (Org.). Equipamentos e materiais didáticos. Brasília: Universidade de Brasília, 2007. 132 p.

GIL, A. C. Métodos e técnicas de pesquisa social. São Paulo: Atlas, 1994. 208 p.

GIL, A. C. Como elaborar projetos de pesquisa. 2. ed. São Paulo: Atlas, 2004.

KAERCHER, N. A. Desafios no ensino de Geografia. 2. ed. Santa Cruz do Sul, RS: EDUNISC, 1998. 146 p.

KENSKI, V. M. Tecnologias e ensino presencial e à distância. Campinas, SP: Papirus, 2008.

LAKATOS, E. M.; MARCONI, M. de A. Metodologia do trabalho científico. São Paulo: Atlas, 1987.

LIMA, R. S. M. Tecnologias educacionais como suporte para o processo de aprendizagem de língua inglesa: aspectos relevantes. Revista Tecnologias na Educação, Campina Grande, PB, Ano 5, n. 8, 2013. Disponível em: http://tecedu.pro.br/wpcontent/uploads/2015/07/Art3-ano5-vol8-julho2013.pdf. Acesso em: 23 set. 2018. Acesso em: 12 set. 2018.

LIMA, T. C. S. de; MIOTO, R. C. T. Procedimentos metodológicos na construção do conhecimento científico: a pesquisa bibliográfica. Revista Katál, Florianópolis, v. 10, p. 37-45, 2007. Número Especial.

LUZ, A. A. B. S. Produção de materiais e sistemas de ensino. Curitiba: InterSaberes, 2016. 206 p.

MACHADO, F. C.; LIMA, M. de F. W. P. O uso da tecnologia educacional: um fazer pedagógico no cotidiano escolar. Scientia cum industria, Caxias do Sul, RS, v. 5, n. 2, p. 44-50, 2017.

MIRANDA, J. C. Uso de novas tecnologias no ensino. Revista Educação Pública, Rio de Janeiro. 2017. Disponível em: http://educacaopublica.cederj.edu.br/revista/artigos/uso-denovas-tecnologias-no-ensino. Acesso em: 29 set. 2018.

MORAN, J. M. A educação que desejamos: novos desafios e como chegar lá. Campinas, SP: Papirus, 2007. 174 p. 
NAPOLITANO, M. Como usar o cinema na sala de aula. 5. ed. São Paulo: Contexto, 2013. $251 \mathrm{p}$.

PENHA, J. M. da; MELO, J. A. B. de. Geografia, novas tecnologias e ensino: (re)conhecendo o "lugar" de vivência por meio do uso do google earth e google maps. GeoUERJ, Rio de Janeiro, n. 28, p. 116-151, 2016.

PEREIRA, F. I. F. O ensino de Geografia e as novas tecnologias: as perspectivas dos jogos eletrônicos como recurso metodológico. Revista Brasileira Educação Geográfica, Campinas, SP, v. 2, n. 4, p. 173-191, jul./dez., 2012.

QUiNTAO, A. F. B.; ALBUQUeRQUE, M. A. M. Desafios e perspectivas do ensino de Geografia no Brasil. In: ENCONTRO NACIONAL DE PRÁTICA DE ENSINO EM

GEOGRAFIA, 10., 2009. Porto Alegre. Anais... Porto Alegre: Universidade Federal do Rio Grande do Sul (UFRG), 2009.

REIS, J. B. A. O conceito de tecnologia e tecnologia educacional para alunos do ensino médio e superior. In: CONGRESSO DE LEITURA DO BRASIL, 13., 2010, Campinas, SP. Anais... Campinas, SP: Universidade de Campinas (UNICAMP), 2010. Disponível em: http://www.alb.com.br/anais17/txtcompletos/sem16/COLE_932.pdf. Acesso em: 23 set. 2018.

ROCHA, F. M. de S.; BERNARDINO, V. M. P. A contribuição das novas tecnologias e suas linguagens no ensino de cartografia escolar. In: PARANÁ. Governo do Estado. Os desafios da escola pública paranaense na perspectiva do professor PDE. 2014. Disponível em: http://www.diaadiaeducacao.pr.gov.br/. Acesso em: 1 nov. 2018.

ROCHA, H.; MONTOVANI, J. C.; COSTA, M. C. Assistindo a Geografia: o uso de filmes como recurso didático para o ensino geográfico. Geografia Ensino \& Pesquisa, Santa Maria, RS, v. 21, n.1, p. 157-166, 2017.

SILVA, J. C. T. Tecnologia: conceitos e dimensões. In: ENCONTRO NACIONAL DE ENGENHARIA DE PRODUÇÃO, 2002, Curitiba. Anais... Curitiba: Associação Brasileira de Engenharia de Produção (ABEPRO), 2002. Disponível em: www.abepro.org.br/biblioteca/enegep2002_tr80_0357.pdf. Acesso em: 2 set. 2018.

TEIXEIRA, I. A. C. (Org.). A diversidade cultural vai ao cinema. Belo Horizonte: Autêntica, 2006.

TOMITA, L. M. S. O saber e o sabor no ensino de Geografia. In: ANTONELLO, I. T; MOURA, J. D. P; TSUKAMOTO, R. Y. (Orgs.). Múltiplas Geografias: ensino, pesquisa, reflexão. Londrina, PR: Edições Humanidade, 2006. p. 29-47. 280 p. V. 3.

VESENTINI, J. W. Educação e ensino de Geografia: instrumento de dominação e/ou de libertação. In: CARLOS, A. F. et al. (Orgs.). A Geografia na sala de aula. São Paulo: Contexto, 1999. p. 14-33. 144 p.

VESENTINI, J. W. Repensando a Geografia Escolar para o século XXI. São Paulo: Plêiade, 2009. 161 p. 
VIEIRA, M. M. Educação e novas tecnologias: o papel do professor nesse cenário de inovações. Revista Espaço Acadêmico, São Paulo, n. 129, p. 95-102, fev. 2012. Disponível em: http://ojs.uem.br/ojs/index.php/EspacoAcademico/article/viewFile /14359/8641. Acesso em: 12 out. 2018.

VOIGT, E.; GIORDANI, A. C.; BEZZI, M. L. Geografia escolar e interação com as tecnologias da educação e comunicação (TICS). In: XVI ENCONTRO NACIONAL DE GEÓGRAFOS, 2010, Porto Alegre. Anais... Porto Alegre: Universidade Federal do Rio Grande do Sul (UFRGS), 2010.

${ }^{i}$ SANCHO, J. M. Para uma tecnologia educacional. Porto Alegre: Artmed. 1998. 